\title{
Proliferation and surface marker characterization of adipose stem cells after culture in various processed outdated platelets lysate containing media
}

\author{
${ }^{1}$ Puji Sari, ${ }^{2}$ Evah Luviah, ${ }^{3}$ Reza Yuridian Purwoko, \\ ${ }^{4,5 *}$ Jeanne Adiwinata Pawitan
}

1Department of Medical Biology, Faculty of Medicine, Universitas Indonesia, Jakarta, Indonesia.

${ }^{2}$ Biomedical Science Master Programme, Faculty of Medicine, Universitas Indonesia, Jakarta, Indonesia.

${ }^{3}$ Erpour Skin Care, Jakarta-Indonesia,

${ }^{4}$ Department of Histology, Faculty of Medicine, Universitas Indonesia, Jakarta, Indonesia.

${ }^{5}$ Stem Cell Medical Technology Integrated Service Unit, Cipto Mangunkusumo Central Hospital-Universitas Indonesia, Jakarta Indonesia.

\begin{abstract}
Human adipose derived stem cells (hADSCs) can be cultured in outdated platelet lysate (PL) containing medium. Processing of thrombocyte concentrate to get PL can be done by various freeze-thaw cycles. There was no information whether various processed PL containing media gave the same proliferation potential and surface marker expressions. Therefore, the aim of this study was to know the proliferation and surface marker characteristics of hADSCs after expansion in various processed PL containing media. hADCSs were cultured in various processed PL containing media, namely F1, F2, and F3, where the numbers denoted once, twice and three times freeze-thaw cycles. Proliferations were measured on day-2, day-4, day-7, and day-10. Positive surface markers were CD90, CD73, and CD105, while negative markers were a cocktail of CD34, CD45, CD11b, CD19, and HLA-DR. Difference in proliferations and surface marker expressions between F1, F2, and F3 were analyzed by one-way ANOVA.

We found that cell proliferation in F1, F2, and F3 showed no significant difference on day-7 and day-10. The expression levels of CD90 and CD 105 in F1, F2, and F3 were all above 90\%, which correspond with mesenchymal stem cells according to the requirement of International Society for Cell Therapy (ISCT). However, CD73 showed highest (97\%) expression on F2 and lowest on F3 (81.8\%). Negative marker range was 2.4-2.9\%. In Conclusion, at the end of culture, hADSCs showed similar profile and proliferation, when cultured in F1, F2, and F3.
\end{abstract}

Keywords: outdated thrombocyte concentrate, freeze-thaw cycles, platelet lysate, stem cells. 


\section{Introduction}

Human adipose derived-stem cells hold a great therapeutic potential for future use as regenerative medicine and tissue engineering. ${ }^{1,2}$ Human adipose-derived stem cells (hADSCs) can be isolated from adipose tissue $^{3,4}$ and are frequently propagated in basal culture medium supplemented with fetal bovine serum (FBS). ${ }^{5}$ The usage of FBS as a medium-supplement in hADSC culture is widespread due to its content that can support growth and proliferation of human mesenchymal stem cell culture. ${ }^{6}$ FBS provides various hormones, growth factors and cytokines, attachment and attachment factors, fatty acid and lipids, vitamins, and trace elements. ${ }^{6}$ Recent years, using FBS as supplement encountered many disadvantages. Besides concerns of animal welfare, there are risks of possible contamination of viruses, prions, bacteria, mycoplasma, nanobacteria, yeast, fungi, and endotoxins, and some of them are impossible to remove from the serum. ${ }^{7}$ Moreover, FBS recently are identified to contain xeno-protein that could not be removed, i.e. N-Glycolylneuraminic acid (Neu5Gc), ${ }^{8,9}$ which might be harmful if the stem cells are intended to be used as therapy in human.

Human platelet/thrombocyte concentrates-derived platelet lysate (hPL) is the one of alternative to overcome shortcomings usage of FBS and the use of hPL is becoming popular as substitute of FBS in cell culture medium..$^{10-15}$ Thrombocyte concentrates have a shelf life of 5 days, and after that they are outdated for clinical use. ${ }^{16}$ It has been shown that outdated thrombocyte concentrates still contain various growth factors. ${ }^{17,18}$

Protocols for growth factor release from $\alpha$-granules of platelet are variable. Processing of platelets into platelet lysate can be performed by freezing the platelets at low temperature i.e. $-20^{\circ} \mathrm{C},-40^{\circ} \mathrm{C},-30^{\circ} \mathrm{C},-70^{\circ} \mathrm{C}$, or $80^{\circ} \mathrm{C}$. ${ }^{19}$ Using low temperature at $-20^{\circ} \mathrm{C}$ to freeze platelets is the easiest way to prepare platelets before use in cell culture medium, as no ultra low freezer is needed. Most of studies only examined the impact of outdated platelet lysate for once or twice or three cycles of freeze thaw. To date, there is no comparison data concerning which processing method yields superior platelet lysate for cell culture medium, the once, twice or three times freeze thaw cycles. Therefore, the aim of this study was to know the proliferation and surface marker characteristics of hADSCs after expansion in one, twice, or three times freezed-thawed outdated PL containing medium, before the hADSCs were be applied further in therapy of various diseases.

\section{Experimental}

This study was done in the Department of Biology, Faculty of Medicine, Universitas Indonesia, in November 2014. The study was conducted in accordance with ethics committee of the Cipto Mangunkusumo Hospital, Faculty of Medicine, Universitas Indonesia. hADSCs were isolated from adipose tissue samples collected from lipoaspirate waste after liposuction, which were obtained from Erpour Clinic, (Kramat, Jakarta). Outdated thrombocyte concentrates were obtained from Indonesian Red Cross-Blood Bank (Kramat, Jakarta).

\section{Preparation of outdated platelet lysate and culture medium}

After the date of expiration, thrombocyte concentrates ( $\mathrm{AB}$ blood group) were prepared immediately to produce platelet lysate. Outdated thrombocyte concentrates were aliquoted $1 \mathrm{~mL}$ to cryo-vials (Biologix, USA) and were subjected to freezing at $-20^{\circ} \mathrm{C}$ for 30 minutes and thawed at room temperature for 10 minutes. The freeze-thaw cycles were done in once (F1), twice (F2), and three times (F3). Then each tube was labeled (F1, F2, F3) and stored at $-20^{\circ} \mathrm{C}$ until use. To make an outdated platelet lysate containing medium, aliquoted tube labeled with F1, F2, and F3 were thawed in room temperature for 10 minutes. Aliquoted platelet lysate could be centrifuged at $6000 \mathrm{rpm}$ for 5 minutes to remove the platelet fragments before use. After centrifugation, supernatant (10\% of total volume media) was then added to media that contained Dulbeco's modified Eagle medium (DMEM)-high glucose (Cat. 11965092, Gibco, USA), and a final concentration of heparin (2 units $/ \mathrm{mL})$, pennicillin $(100 \mathrm{U} / \mathrm{mL})$-streptomycin $(100 \mu \mathrm{g} / \mathrm{mL})$, and fungizone $(125 \mu \mathrm{g} / \mathrm{mL})$ (Life Technologies, USA). The media was then filtered through $0.45 \mu \mathrm{M}$ and $0.22 \mu \mathrm{M}$ syringe filters (Sartorius, USA), to become F1, F2, and F3 culture medium.

\section{hADSC isolation}

Isolation of hADSC from lipoaspirate was carried out using enzymatic method as described previously. ${ }^{3,4}$ Briefly, the lipoaspirate was filtered using a coffee filter. Coffee filter containing fat tissue was 
washed 3-5 times by soaking in a sterile porcelain bowl, which was half filled with phosphate buffered saline (PBS). After adipose tissue appeared yellowish and clear, it was digested with $0.075 \%$ collagenase type I (Gibco, USA) in $\mathrm{CO}_{2}$ incubator at $37^{\circ} \mathrm{C}, 5 \% \mathrm{CO}_{2}$ with manual shaking every 5 minutes. The digested tissue was centrifuged and the infranatant was filtered using $100 \mu \mathrm{m}$ nylon mesh filter (Beckton Dickinson, USA). The filtrate was then centrifuged (1200 rpm, 10 minutes), the remaining red blood cells were lysed with lysis buffer for 15 minutes incubation at room temperature. The isolated cells were then expanded $\left( \pm 45.000 \mathrm{cells} / \mathrm{cm}^{2}\right)$ in F1, F2, F3 culture medium or 10\% FBS containing medium as comparison. Expanded hADSC was detached using TrypLE Select (Cat.12563011, Life Technologies, USA), and harvested. The proliferation assay and flowcytometry analysis were done when cells reach passage 3.

\section{Cell proliferation assay}

Cells were seeded with a density of $1 \times 10^{3}$ cells/well and cultured in 96 wells with a number of repetitions of 12 wells for each F1, F2, and F3 medium. The cell viability assays were performed using 3-(4,5dimethylthiazol-2-yl)-5-(3-carboxymethoxyphenyl)-2-(4-sulfophenyl)-2H-tetrazolium (MTS) assay (cat. G3580, Promega-USA). Cell culture medium was then removed and cells were washed with PBS (Dulbecco's Phosphate Buffer Saline, Life technologies, USA), and MTS working solution was added according to the manufacturer's instructions. The cells were incubated for 3 hours at $37^{\circ} \mathrm{C}, 5 \% \mathrm{CO}_{2}$. The optical density (OD) 490 was measured at day 2, 4, 7, and 10. The OD values were converted to the number of cell yield using extrapolation. The numbers of cells for each culture-duration were then presented in a graph and were analyzed using one-way ANOVA to compare cell proliferations on day 2, 4, 7 and 10 that cultured in F1, F2, and F3 medium.

\section{Surface marker expression analysis using flowcytometry}

Surface marker analysis were assessed using FACS Calibur (Beckton Dickinson, USA) and were determined by commercially available BD Stemflow human mesenchymal stem cells (hMSC) detection kit (Cat.562245, Beckton Dickinson, USA). Cells that were cultured in medium F1, F2, F3, and FBS were detached and cell pellets were re-suspended and washed in sterile PBS (Life technologies, USA) at a minimum concentration of 100.000cells/tube. Appropriately labeled antibody against MSC markers were added according to the manufacturer's instructions. Monoclonal antibodies against CD73-APC, CD90-FITC, CD105-PECy5.5 as positive cocktail, and CD34-PE, CD-45PE, CD11b-PE, CD19-PE, HLA-DR PE as negative cocktail were used. Flow cytometry analysis was performed on 10.000 cells per sample (10.000 gated events). Unstained cells that were cultured in each of F1, F2, F3, and FBS containing medium were used to correct gating of cell population of interest and to eliminate debris. Positive and negative isotype controls were used to determine the base line.

\section{R e s u Its}

\section{Human adipose-derived stem cell culture}

Cells started to attach and showed fibroblastic-like shapes at day-3 after initial seeding and cultured in F1, F2, or F3 culture medium (passage 0) (Figure 1A). Cells were then harvested after they were confluent with uneven distribution (data not shown) after 13 days of seeding. Cells started to attach at day- 1 observation and harvested at day-4 at passage 1 (data not shown). The day of cells started to attach and harvested were different from sample to sample (data not shown) depended on number of cell yields after isolation. Cell distribution was more evenly at passage 3 , and reached confluent and harvested at day-5 (Figure 1B, 1C). The days of culture duration to reach confluent depended on the number of seeded cells.

Initial seeding for passage 0 was not done in FBS containing medium due to limited cell number yield after isolation process, or limited adipose tissue samples. Cells cultured in FBS containing medium was done at passage 1 after the first harvest (sub-cultured). Cell morphologies were different when cultured in DMEM high glucose medium that was supplemented with FBS. Compared to F1, F2 and F3 medium, cells that were cultured in FBS containing medium seemed larger in size and did not grow or proliferate appropriately, and after 13 days of culture (Figure 2A, 2B, 2C), cells did not become confluent. Nevertheless, cells cultured in FBS containing medium was harvested at day 13 of culture and was subjected to flow cytometry analysis, but not subjected to proliferation assay due to limited cell number. 
A

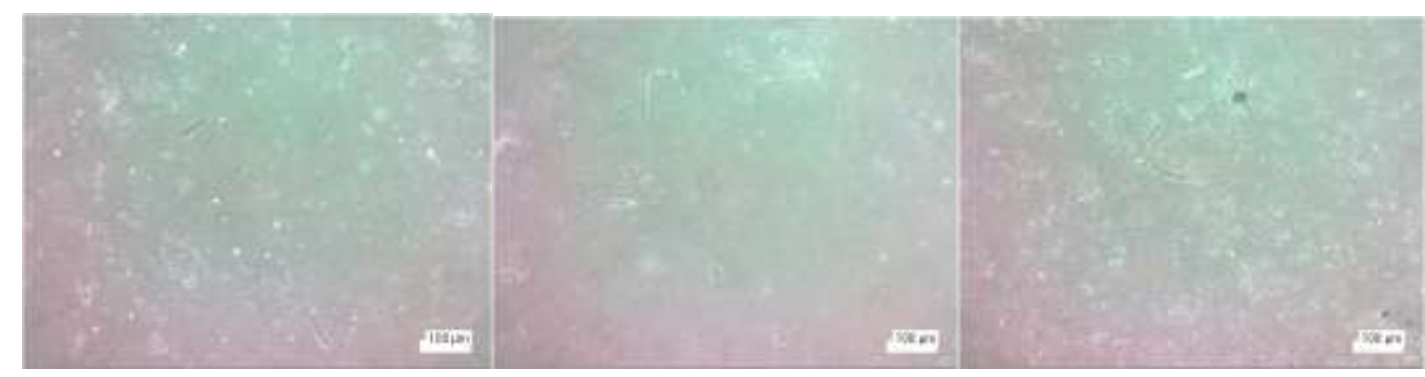

B

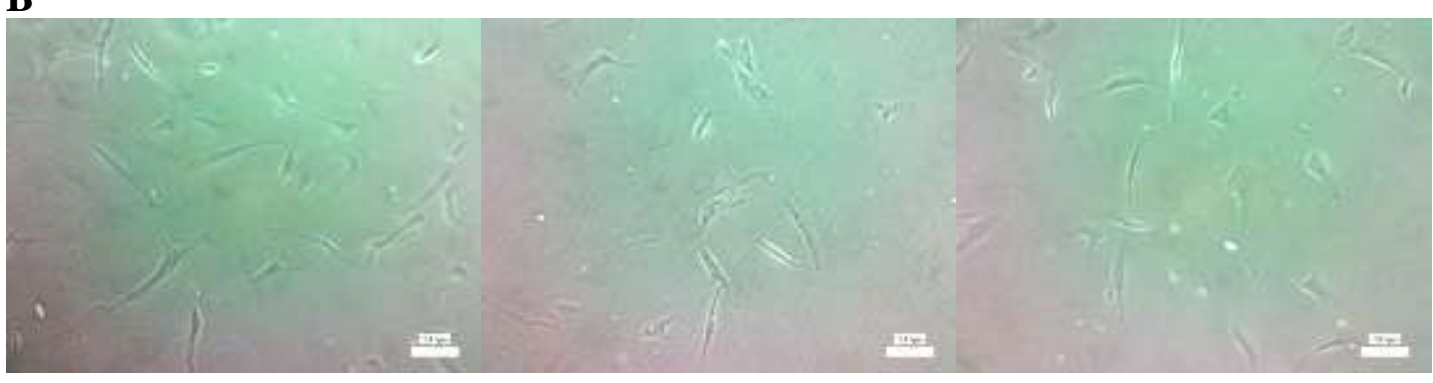

C

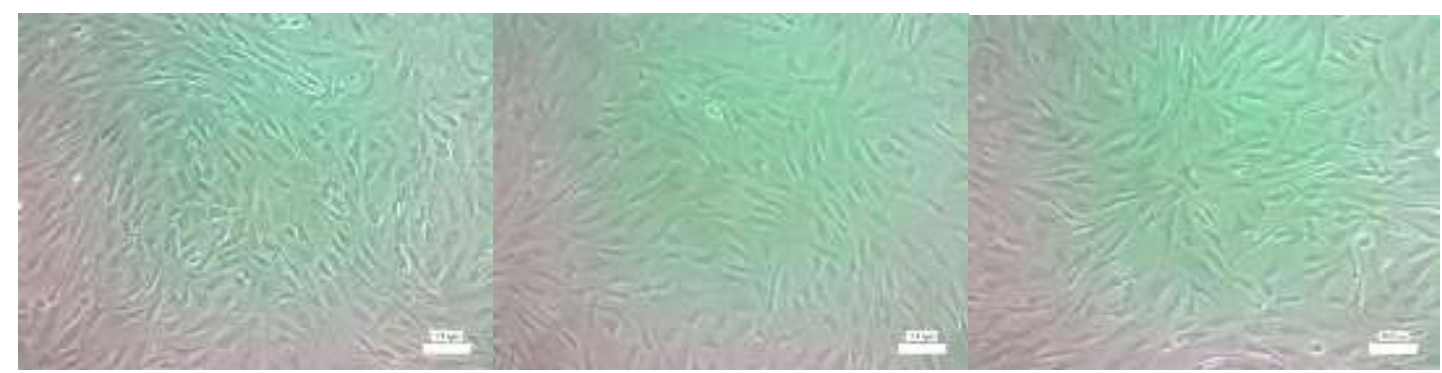

Figure 1. hADSC cultured in F1, F2, and F3 medium

$\mathrm{A}=3$ days after isolation (Ps-3, P0), B = 2 days after seeding (Ps-2, P3), C = 5 days after seeding, cells became confluent and harvested (Ps-2, P3), left to right: F1, F2, F3, scale bar: $100 \mu \mathrm{M}$, Ps= sample, P= passage.

\section{Cell proliferation after expansion in F1, F2, and F3 medium}

The effect of F1, F2, and F3 culture medium on cell proliferation was presented in Figure 3. Proliferation of hADSCs gradually increased in F1, F2, and F3 culture medium, where the concentration of outdated platelet lysate was $10 \%$. Cell proliferation was significantly different at day-2 and day-4 when cells were cultured in F1, $\mathrm{F} 2$, and F3 medium $(\mathrm{P}<0.05)$ (Figure 3). 
A

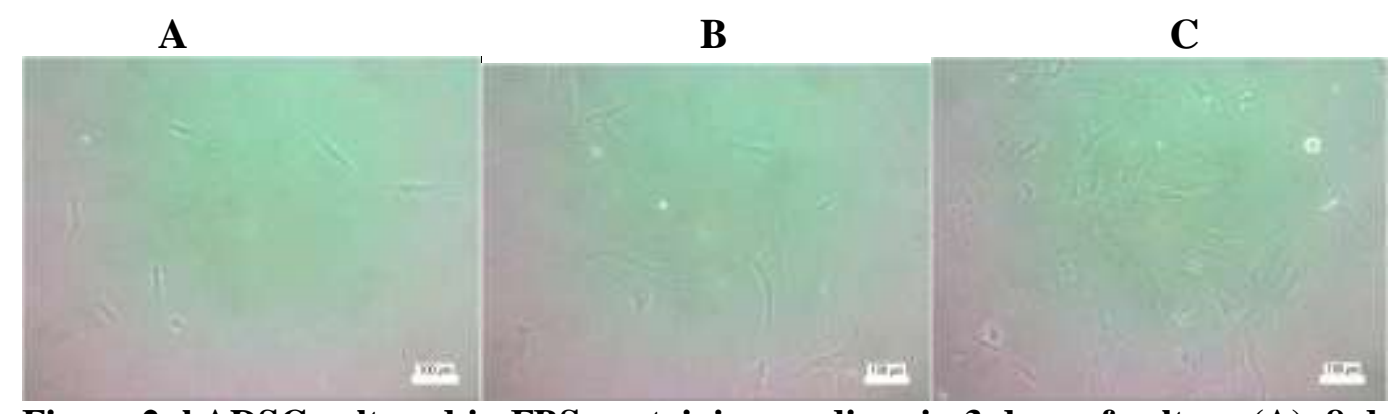

Figure 2. hADSC cultured in FBS containing medium in 3 days of culture (A), 8 days of culture (B) and 13 days of culture $(C)$

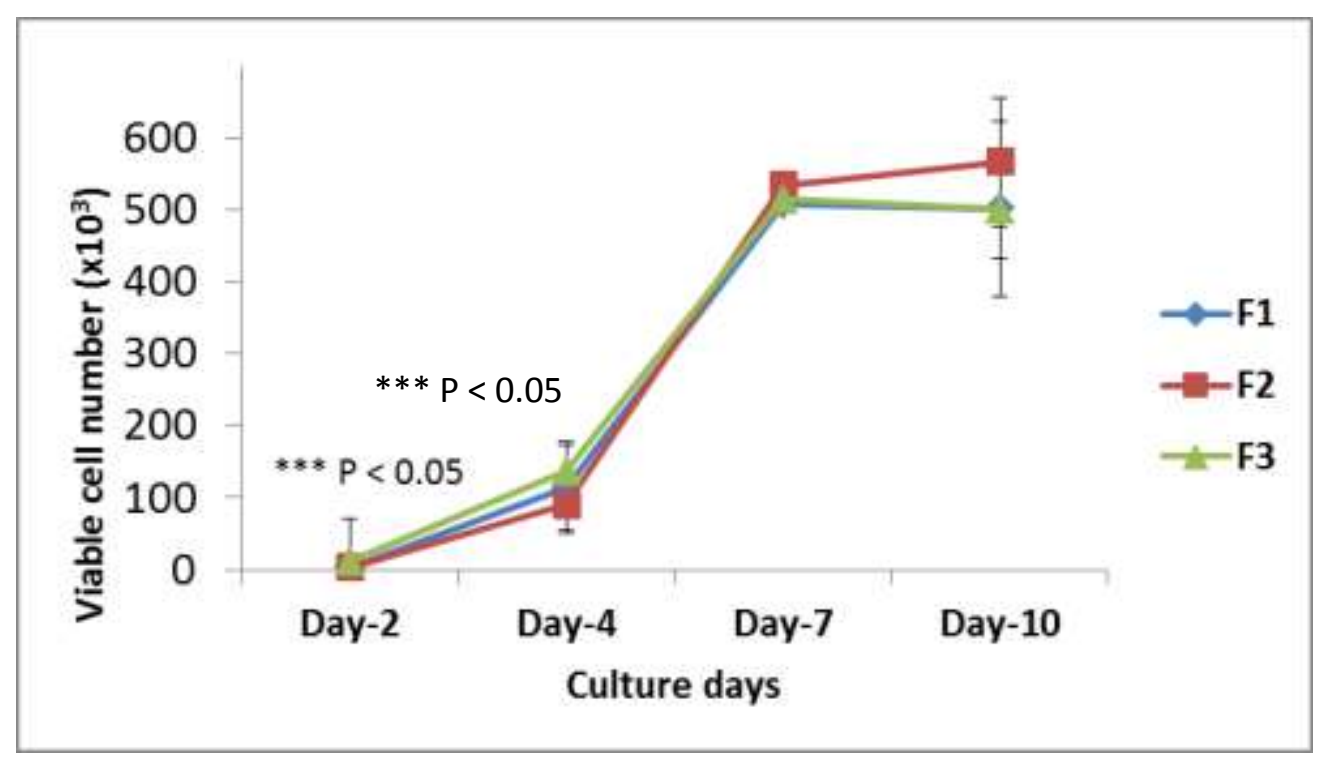

Figure 3. Cell proliferation after expansion in F1, F2, and F3 medium $* * * \mathbf{p}<0.05=$ significant difference.

Cells reached maximum viable cell number at day-7 of culture for F1 and F3 medium, but for F2 medium, cells reach maximum viable number at day-10. In F1 and F3 medium, cell proliferation between day-7 and day-10 of culture started to reach stationary phase followed by a decline phase. There was no significant difference in cells proliferation on day-7 and day-10 in F1, F2, and F3 medium $(\mathrm{P}<0.05)$.

\section{Surface marker expression analysis of hADSC cultured in F1, F2, F3, and FBS containing medium}

Four independent primary cell cultures (hADSC) were cultured and propagated in F1, F2, F3, or FBS containing medium. The selected positive surface markers (CD90, CD73, CD105) and negative markers (CD34, CD45, CD11b, CD19, HLA-DR) were determined using flow cytometry. Surface marker expression in F1, F2, F3 medium, and FBS containing medium can be seen in Table 1.

We found that hADSCs cultured in F3 medium showed the highest expression of CD90 (96\%) and the lowest expression of CD73 (81.8\%). Negative marker showed highest (2.9\%) expression on ADSC cultured in F3 medium. ADSC has the highest (89.6\%) expression of CD73 when cultured in F1 and F2 containing medium. hADSC cultured in FBS showed the lowest expression of all selected positive surface marker (below $30 \%$ ) and had the highest negative marker expression (3.3\%). There was no statistically difference in hADSC surface marker expressions when cultured in F1, F2, and F3 medium. 


\section{D iscussion}

In this study, we found that F1, F2, and F3 medium had potentials to promote cell proliferation. Cells reach viable cell number's peak at day-7 and day-10 of culture (> 500.000 cells/well) in F1, F2, and F3 culture medium (Figure 3). The results of this study, to a certain extent is quite similar with the result of Kolle et al, ${ }^{20}$ which stated that mesenchymal stem cells gave positive effect on proliferation at day 7 .

A study by Mishra et $\mathrm{al}^{21}$ stated that human fibroblast cells showed dramatic increase in cell number (> 600.000 cells) with 10.000 cells/well at first seeding when the platelets were buffered with physiologic $\mathrm{pH}$ using $8.4 \%$ sodium bicarbonate after centrifugation before use as supplement without any platelet activation with thrombin or calcium, while we used platelet lysate. Mishra et $\mathrm{al}^{21}$ found a five-fold increase in cell proliferation, when compared to FBS due to release of growth factors from platelet during centrifugation process. Moreover, non-activated or non-lysed platelets would be activated by collagen when used as culture medium of human fibroblasts, because fibroblasts would secrete abundant amount of collagen, which serve as a potent activator of platelets. ${ }^{22}$

Table 1. Surface marker expressions of hADSCs cultured in F1, F2, F3 medium, and FBS containing medium

\begin{tabular}{|c|c|c|c|c|c|}
\hline Medium & Sample & CD90 & CD73 & CD105 & $\begin{array}{l}\text { Neg (CD34, } \\
\text { CD11b, CD19, HLA-DR) }\end{array}$ \\
\hline \multirow[t]{5}{*}{$\overline{F 1}$} & Ps-1, p3 & 99.8 & 97.1 & 97.1 & 0.2 \\
\hline & Ps- $2, \mathrm{p} 3$ & 96.5 & NA & 96.8 & 4.8 \\
\hline & Ps-2, p5 & 94.9 & NA & 97.2 & 3.9 \\
\hline & Ps-3, p3 & 79.8 & 82.2 & 81.7 & 1.1 \\
\hline & Mean & 92.7 & 89.6 & 93.2 & 2.5 \\
\hline \multirow{5}{*}{ F2 } & Ps-1, n3 & 998 & 970 & 962 & 09 \\
\hline & Ps $-2, p 3$ & 96.6 & NA & 97.8 & 3.0 \\
\hline & Ps-2, p5 & 94.8 & $\mathrm{NA}$ & 96.7 & 2.1 \\
\hline & Ps-3, p3 & 86.3 & NA & 73.6 & 3.6 \\
\hline & Mean & 94.4 & 97.0 & 91.1 & 2.4 \\
\hline \multirow[t]{5}{*}{ F3 } & Ps-1, p3 & 99.7 & 94.9 & 94.8 & 0.9 \\
\hline & Ps-2, p3 & 95.2 & NA & 96.6 & 2.5 \\
\hline & Ps-2,p5 & 95.8 & NA & 96.4 & 3.0 \\
\hline & Ps-3, p3 & 93.5 & 68.7 & 84.3 & 5.4 \\
\hline & Mean & 96.0 & 81.8 & 93.0 & 2.9 \\
\hline FBS & Ps-3, p3 & 36.3 & 12.3 & 31.0 & 3.3 \\
\hline
\end{tabular}

$\mathrm{F}=$ platelet lysate containing medium, 1-3= number of freeze-thaw cycles, $\mathrm{FBS}=$ fetal bovine serum containing medium, $\mathrm{Ps}=$ sample, $\mathrm{p}=$ passage

In our study, 1000 cells/well as the seeding number revealed that hADSC culture showed dramatic cell proliferation at day-4 and day-7. Another study by Shani et al ${ }^{23}$ performed comparative study between activated platelet using $10 \% \mathrm{CaCl}_{2}$ and human thrombin $(1: 10[\mathrm{v} / \mathrm{v}])$ and non-activated platelet, and reported that cell proliferations reached the peak of proliferation at 8 days after culture of human bone marrowmesenchymal stem cells with viable cell numbers of $>60.000$ cells with a seeding number of $>10.000$ cells/well. They also stated that there was no difference in cell proliferation between activated and nonactivated platelet. However, in our study, at day-7, viable cell number reach > 500.000 cells/well on F1, F2, and F3 medium. Shani et $\mathrm{al}^{23}$ added medium only once at the beginning of culture without medium change through all experiment. Without frequent medium change, the culture might lead to generation of metabolite/waste products, mainly lactate and ammonia that lead to decrease in cell growth rate. ${ }^{24}$

Pham et $\mathrm{al}^{25}$ reported that ADSC cultured in activated platelet with $20 \% \mathrm{CalCl}_{2}$ started to increase their proliferation rate after 3 days of culture and tend to rise to a maximum at day-7, and ADSC still growth until 11 
days of culture with a lower trend in proliferation. In our study, hADSC started to show an increase in viable cell numbers at the beginning of culture, and reach a maximum at day-7 (F1, F2, F3 medium), while cells continued to grow at day-10 only on F2 medium.

Moreover, differences on seeding number at the beginning of culture on F1, F2, and F3 medium might lead to the differences between proliferation on day 2 and day 4 . The seeding number over 3000 cells/well and below 10000 cells/ well (data not shown) gave the best trend of proliferation rate on F2. Seeding number below 3000 cells/well gave a maximum increase in viable cell number at day-4 of culture on F1. However, seeding number over 10,000 cells/ well gave the lowest increase in viable cell number at day-4 of culture on F3 medium. After day-4 onwards, there was no dramatically increase in viable cell number and the cell growth started to reduce on F1 and F3 at day 10.

A study conducted by Atashi et $\mathrm{al}^{26}$ stated that non-activated was more effective than thrombin (1:10) activated to enhance hADSC multiplication. A 155 -fold increase in viable cell number occurred within 10 days after culture without medium change. Atashi et al ${ }^{26}$ used autologous platelet in $20 \%$ concentration $\left(2.41 \times 10^{5} \pm\right.$ 20.36 platelets/ $\mu \mathrm{L}$ ). The platelet was directly cultured with hADSC without getting through $0.22 \mu \mathrm{M}$ syringe filter and allowed to get gradually activated during 10 days of culture. Lack of standardization and agreement in efficiency were the limitation in Atashi et $\mathrm{al}^{26}$ study. Each autologus platelet could have different characteristics along with preparation technique. ${ }^{27}$

Schallmoser et al ${ }^{28}$ reported that mesenchymal stem cells/progenitor cells reached peak growth at 7 days after culture in outdated platelet lysate. In Schallmoser et al study, pooled platelet concentrates were subjected to one freeze-thaw cycle at $-80^{\circ} \mathrm{C}$ followed by storing at $-80^{\circ} \mathrm{C}$ before use. Griffiths et al ${ }^{29}$ stated that hMSC from bone marrow reached peak growth at 10 days after culture in medium that contained twice freeze ($\left.20^{\circ} \mathrm{C}\right)$-thawed $\left(37^{\circ} \mathrm{C}\right)$ outdated platelet lysate. Rauch et al ${ }^{30}$ studied the effect of outdated platelet lysate to hADSC culture. The centrifuged platelet concentrate was re-suspended in $0.9 \% \mathrm{NaCl}$, and then subjected to three times freeze-thaw cycles at $-20^{\circ} \mathrm{C}$ followed by storage the lysate at $-20^{\circ} \mathrm{C}$ before use. Rauch et al ${ }^{30}$ study confirmed that hADSC culture reached peak cell number at day-7 of culture with a density of $100 \mathrm{cells} / \mathrm{mm}^{2}$ (3200 cells/ well) at the first day of seeding, and started to reach stationary phase at day-9 of culture. Their study results ${ }^{28-30}$ were in agreement with our results.

In our study, comparison of hADSCs cultured in F1, F2, and F3 medium showed a same trend in proliferation. A review on many studies showed that different platelet lysate preparation technique confirmed that cells started to increase in cell number on day-2 onwards and reach maximum proliferation rate at day-7 of culture, and still grew until 11 days of culture in $10 \%$ platelet lysate/releasate, while several studies reported that $5 \%$ concentration was sufficient to enhance cell proliferation rate. ${ }^{11}$ Number of viable cells might vary from day to day of cultures depending on first seeding number and cell maintenance i.e. replacing with fresh medium every 2-3 days of culture.

Besides proliferation capacity, other characteristics such as surface markers of hADSCs after expansion in F1, F2, and F3 medium need to be done. In this study, according to their surface masrkers, hADSCs that derived from adipose tissue after liposuction might be regarded as multipotent mesenchymal stromal cells. International Society for Cell Therapy (ISCT) has defined the minimal criteria of multipotent mesenchymal stromal cells, proposed by Dominici et al $^{31}$ that mesenchymal stem cells should express ( $\left.\geq 95 \%\right)$ CD90, CD73, CD105, and lack the expression $(\leq 2 \%)$ of CD34, CD45, CD14, CD11b, C79 $\alpha$ or CD19, and HLA-DR.

In this study, we performed flow cytometry analysis to assess the expression of surface markers of hADSCs after expansion in F1, F2, F3 medium, and FBS containing medium. In this study, all culture in F1, F2, and F3 medium showed positive mesenchymal stem cell markers, which all were above $90 \%$, except expressions of CD73 that were all above $80 \%$, which was in accordance to the requirements of MSC-based product as Investigational New Drug Applications (INDs) for clinical trials. ${ }^{32}$ According to Mendicino et al, ${ }^{32}$ for clinical trials, the minimum range of expression levels of CD105, CD90, and CD73 should be above 80\% and thus, our results were still corresponding with the MSC criteria for clinical trial.

Our study was similar to the study conducted by Kolle et al, ${ }^{20}$ which confirmed that hADSC cultured in human platelet lysate give high level expressions of CD105, CD90, and CD73, which all were over 90\%. Kolle et al ${ }^{20}$ produced platelet lysate by one cycle of freezing at $-40^{\circ} \mathrm{C}$ and thawing at $37^{\circ} \mathrm{C}$. However, in contrast 
with our study, Kolle et al ${ }^{20}$ showed a high level of three positive surface markers of hADSC cultured in FBS medium.

In our study, the very low number of positive surface marker expressions in FBS supplemented medium might correspond to the quality of FBS and hADSC culture result. Cells that were grown in FBS containing DMEM high glucose showed larger size, low multiplication capacity (Figure 2), and failed to become confluent even after 13 days of culture compared to cells that were grown in F1, F2, and F3 medium. Naaijkens et al ${ }^{33}$ also showed a lower mean of the three positive surface markers on hADSC that was cultured in FBS containing medium compared to platelet lysate. The hADSC cultured in FBS also showed larger size in morphology, similar with our study. Cell size is an important factor especially when cells are injected intravenously, since larger cells can lead to obstruction of the lung. ${ }^{34}$ It has been indicated that cells with a smaller cell size have a higher differentiation capacity. ${ }^{35}$

The inability of hADSC to become confluent when cultured in FBS containing DMEM high glucose medium might be due to higher ROS production and thus could promote cell death. ${ }^{36,}{ }^{37}$ On the other hand, hADSC that was cultured in platelet lysate containing DMEM high glucose or low glucose showed good results (data not shown). It has been confirmed that platelet derived products (platelet lysate or releasate) have antiapoptotic effects on cells and thus could rescue the cells from death. ${ }^{38}$

Our experiment result was similar with the study conducted by Pawitan et al, ${ }^{12}$ which showed a lower level of CD73 expression, and a higher level of CD90 expression.

Moreover, a study showed that hADSC cultured in platelet lysate underwent spontaneous differentiation into chondrogenic and adipogenic lineage in prolonged culture. ${ }^{13}$ In our experiment, hADSC cultured in F1, F2, and F3 culture medium, but not those in FBS containing medium, tended to spontaneously differentiate into chondrogenic cells (data not shown).

Our observation is also in quite agreement with Paula et $\mathrm{al}^{39}$ study that showed similar characteristics for hADSC that was cultured in pooled ABO group human serum. We observed that hADSC morphology that was cultured in F1, F2, and F3 medium (Figure 2B) had smaller size, much denser growth, and lower granularity or complexity that was confirmed by side scatter (SSC) and forward side scatter (FSC) on flow cytometry (data not shown).

Moreover, a study showed lower expression of adhesion and cellular matrix-associated molecules in hADSC that was cultured in human serum and thrombin activated platelet, which supported the reduced cell anchorage to plastic surfaces. There was also a reduced expression level of MYC gene as transcription factor for c-MYC protein in hADSC that was cultured in pooled human serum in concomitant with higher passages of hADSC, and this might prevent immortality of hADSC. ${ }^{40}$ Transplanted hADSCs that was cultured in human serum and platelet lysate on mice did not lead to tumorigenesis, in contradiction with transplanted hADSC that was cultured in FBS, which formed tumorigenesis. ${ }^{39}$ To be used as therapy in patients, it is not appropriate to generalized platelet lysate containing cell culture study results. Therefore, MYC expression level and tumorigenesis potential study on our cells need to be addressed in further studies.

Negative surface marker expressions of hADSC that were expanded in F1, F2, and F3 medium were also still in range of MSC-Based Product INDs for clinical trials, ${ }^{32}$ and minimal criteria of MSC proposed by ISCT. ${ }^{31}$ Almost all earlier studies confirmed that platelet lysate as FBS substitute was a good supplement in culture media. ${ }^{39}$ Outdated or fresh platelet lysates were capable to promote proliferation of human adiposederived stem cells, while maintaining hADSC phenotype (surface markers) despite of the variations in platelet lysate preparation. ${ }^{10,20,28,29,33}$

The limitation in this study was the fact that CD73 conjugated APC was not measured in all samples (Table 1), due to inadequate cell number, as a study showed that instrument calibration problems and limited cell number might have an impact on flow cytometry analysis. ${ }^{41}$

In conclusion, at the end of culture hADSCs showed similar profile and proliferation, when cultured in F1, F2, and F3 containing medium. 


\section{Funding}

This study was funded by the grant from Ministry of Education and Culture, Indonesia, (BOPTN) 2014, contract no: DIPA-023.04.2.189658/2014 for conducting the research, and Directorate of Research and Community Service (DRPM), Universitas Indonesia, contract no: 0812SK/R/UI/2016 to defray publication cost.

\section{Acknowledgement}

We thank to integrated laboratory, Faculty of Medicine, Universtas Indonesia for providing flow cytometry analysis.

\section{References:}

1. J.M. Gimble, A.J. Katz and B.A. Bunnell, Circ. Res., 100, 1249 (2007); doi:10.1161/01.RES.0000265074.83288.09.

2. J.A. Pawitan, Cell Tissue Transplant. Therapy, 2, 7 (2009); doi:10.4137/CTTT.S3654.

3. P.A. Zuk, M. Zhu, P. Ashjian, D.A. De Ugarte, J.I. Huang, H. Mizuno, Z.C. Alfonso, J.K. Fraser, P. Benhaim and M.H. Hedrick, Mol. Biol. Cell, 13, 4279 (2002); doi:10.1091/mbc.e02-02-0105.

4. J.A. Pawitan, I.K. Liem, D. Suryani, A. Bustami and R.Y. Purwoko, Asian Biomed., 7, 333 (2013).

5. H. Suga, T. Shigeura, D. Matsumoto, K. Inoue, H. Kato, N. Aoi, S. Murase, K. Sato, K. Gonda, I. Koshima and K. Yoshimura, Cytotherapy, 9, 738 (2007); doi:10.1080/14653240701679873.

6. G. Gstraunthaler, ALTEX, 20, 275 (2003).

7. C. Tekkatte, G.P. Gunasingh, K.M. Cherian and Sankaranarayanan, Stem Cell Int., 2011, 504723 (2011).

8. J.L. Spees, C.A. Gregory, H. Singh, H.A. Tucker, A. Peister, P.J. Lynch, S.-C. Hsu, J. Smith and D.J. Prockop, Mol. Ther., 9, 747 (2004); doi:10.1016/j.ymthe.2004.02.012.

9. A. Heiskanen, T. Satomaa, S. Tiitinen, A. Laitinen, S. Mannelin, U. Impola, M. Mikkola, C. Olsson, H. Miller-Podraza, M. Blomqvist, A. Olonen, H. Salo, P. Lehenkari, T. Tuuri, T. Otonkoski, J. Natunen, J. Saarinen and J. Laine, Stem Cells, 25, 197 (2007); doi:10.1634/stemcells.2006-0444.

10. D. Suryani, J. Pawitan, J. Lilianty, R.Y. Purwoko, I.K. Liem and L. Damayanti, Med. J. Indones., 22, 146 (2013); doi:10.13181/mji.v22i3.583.

11. J.A. Pawitan, Curr. Stem Cell Res. Ther., 7, 329 (2012); doi:10.2174/157488812802481508.

12. J.A. Pawitan, D. Wulandari, D. Suryani, L. Damayanti, R.Y. Reza Yuridian Purwoko and I.K. Liem, Int. J. PharmTech. Res., 5, 1301 (2013).

13. J.A. Pawitan, D. Suryani, D. Wulandari, L. Damayanti, I.K. Liem and R.Y. Purwoko, Int. J. PharmTech. Res., 6, 224 (2014). 
14. J.A. Pawitan, I.K. Liem, E. Budiyanti, I. Fasha, L. Feroniasanti, T. Jamaan and K. Sumapradja, Int. J. PharmTech. Res., 6, 1202 (2014).

15. J.A. Pawitan, L. Feroniasanti, T. Kispa, I.H. Dilogo, I. Fasha, T. Kurniawati et al., Int. J. PharmTech. Res., 7, 354 (2014-2015).

16. WHO, Manual on the management, maintenance and use of blood cold chain equipment. Geneva: WHO; 2005.

17. P. Sari, E. Luviah, Y. Nugraha, J.A. Pawitan, J. Lilianty and R.Y. Purwoko, Indian J., 9, 475 (2014).

18. Y. Nugraha, P. Sari, R.Y. Purwoko, E. Luviah and J.A. Pawitan, Int. J. PharmTech. Res., 6, 2036 (2014).

19. J.A. Pawitan, Curr. Stem Cell Res. Ther., 7, 329 (2012); doi:10.2174/157488812802481508.

20. S.-F. Trojahn Kølle, R.S. Oliveri, P.V. Glovinski, M. Kirchhoff, A.B. Mathiasen, J.J. Elberg, P.S. Andersen, K.T. Drzewiecki and A. Fischer-Nielsen, Cytotherapy, 15, 1086 (2013); doi:10.1016/j.jcyt.2013.01.217.

21. A. Mishra, P. Tummala, A. King, B. Lee, M. Kraus, V. Tse and C.R. Jacobs, Tissue Eng. Part C Methods, 15, 431 (2009); doi:10.1089/ten.tec.2008.0534.

22. S. Amano, Y. Ogura, N. Akutsu and T. Nishiyama, Exp. Dermatol., 16, 151 (2007); doi:10.1111/j.1600$\underline{0625.2006 .00514 . x .}$

23. S. Shani, R.E. Ahmad, S. Vasudevaraj Naveen, M.R. Murali, K. Puvanan, A.A. Abbas and T. Kamarul, Sci. World J., 2014, 1 (2014); doi:10.1155/2014/845293.

24. I. Slivac, V. Blajić, K. Radošević, Z. Kniewald and V. Gaurina Srček, Cytotechnology, 62, 585 (2010); doi:10.1007/s10616-010-9312-y.

25. P. Van Pham, K.H.-T. Bui, D. Ngo, N. Vu, N. Truong, N.L.-C. Phan, D. Le, T. Duong, T. Nguyen, V. Le and N. Phan, Stem Cell Res. Ther., 4, 91 (2013); doi:10.1186/scrt277.

26. F. Atashi, V.S. Beinier, Z. Nayernia, P.B. Cuenod and A. Modaressi, J. Stem Cell Res. Ther., 5, 8 (2015).

27. G. Weibrich, W.K.G. Kleis, G. Hafner and W.E. Hitzler, J. Craniomaxillofac. Surg., 30, 97 (2002); doi:10.1054/jcms.2002.0285.

28. K. Schallmoser and D. Strunk, Methods Mol. Biol., 946, 349 (2013); doi:10.1007/978-1-62703-128$\underline{822}$.

29. S. Griffiths, P.R. Baraniak, I.B. Copland, R.M. Nerem and T.C. McDevitt, Cytotherapy, 15, 1469 (2013); doi:10.1016/j.jcyt.2013.05.020. 
30. G. Gstraunthaler, C. Rauch, E. Feifel, A. Flörl and K. Pfaller, J. Adv. Biotechnol. Bioeng., 2, 39 (2014); doi:10.12970/2311-1755.2014.02.02.1.

31. M. Dominici, K. Le Blanc, I. Mueller, I. Slaper-Cortenbach, F. Marini, D. Krause, R.J. Deans, A. Keating, D.J. Prockop and E.M. Horwitz, Cytotherapy, 8, 315 (2006); doi:10.1080/14653240600855905.

32. M. Mendicino, A.M. Bailey, K. Wonnacott, R.K. Puri and S.R. Bauer, Cell Stem Cell, 14, 141 (2014); doi:10.1016/j.stem.2014.01.013.

33. B.A. Naaijkens, H.W.M. Niessen, H.J. Prins, P.A.J. Krijnen, T.J.A. Kokhuis, N. de Jong, V.W.M. van Hinsbergh, O. Kamp, M.N. Helder, R.J.P. Musters, A. van Dijk and L.J.M. Juffermans, Cell Tissue Res., 348, 119 (2012); doi:10.1007/s00441-012-1360-5.

34. A. van Dijk, B.A. Naaijkens, W.J. Jurgens, K. Nalliah, S. Sairras, R.J. van der Pijl, K. Vo, A.B.A. Vonk, A.C. van Rossum, W.J. Paulus, F.J. van Milligen and H.W.M. Niessen, Stem Cell Res. (Amst.), 7, 219 (2011); doi:10.1016/j.scr.2011.06.003.

35. H.J. Prins, H. Rozemuller, S. Vonk-Griffioen, V.G. Verweij, W.J. Dhert, I.C. Slaper-Cortenbach and A.C.M. Martens, Tissue Eng., 15, 3741 (2009); doi:10.1089/ten.tea.2008.0666.

36. M.L. Circu and T.Y. Aw, Free Radic. Biol. Med., 48, 749 (2010); doi:10.1016/j.freeradbiomed.2009.12.022.

37. T. Yu, B.S. Jhun and Y. Yoon, Antioxid. Redox Signal., 14, 425 (2011); doi:10.1089/ars.2010.3284.

38. A.E. Au, M. Sashindranath, R.J. Borg, O. Kleifeld, R.K. Andrews, E.E. Gardiner, R.L. Medcalf and A.L. Samson, Cell Death Dis., 5, e1410 (2014); doi:10.1038/cddis.2014.373.

39. A.C. Paula, T.M. Martins, A. Zonari, S.P. Frade, P.C. Angelo, D.A. Gomes and A.M. Goes, Stem Cell Res. Ther., 6, 76 (2015); doi:10.1186/s13287-015-0030-4.

40. K. Bieback, V.A. Ha, A. Hecker, M. Grassl, S. Kinzebach, H. Solz, C. Sticht, H. Klüter and P. Bugert, Tissue Eng. Part A, 16, 3467 (2010); doi:10.1089/ten.tea.2009.0727.

41. T. L. Ramos, L.I. Sánchez-Abarca, S. Muntión, S. Preciado, N. Puig, G. López-Ruano, Á. HernándezHernández, A. Redondo, R. Ortega, C. Rodríguez, F. Sánchez-Guijo and C. del Cañizo, Cell Commun. Signal., 14, 2 (2016); doi:10.1186/s12964-015-0124-8. 